\title{
Eficiência de armadilhas de queda (pitfall traps) em amostragens de anfíbios e répteis no Brasil
}

\author{
Sonia Zanini Cechin ${ }^{1}$ \\ Marcio Martins ${ }^{2}$
}

\begin{abstract}
Effectiveness of pitfall traps for sampling amphibians and reptiles in Brazil. The effectiveness of pitfall traps associated with drift fences to capture amphibians and reptiles in three field studies, in Rio Grande do Sul (extreme southern Brazil), São Paulo (São Paulo, southeastern Brazil), and Amazonas (Amazonas, northern Brazil) is described. At Santa Maria, a total of 2040 amphibians and reptiles were caught in 30 pitfalls ( $200 \mathrm{~L}$, with drift fence) during 18 months of study (capture efficiencies of 3.78 amphibians and reptiles/pitfall/month and 0.14 snake/pitfall/month). At Itirapina, São Paulo, 1262 amphibians and reptiles were obtained in 72 pitfalls ( $100 \mathrm{~L}$, with drift fence) during six months (capture efficiencies of 11,9 amphibians and reptiles/pitfall/month and 0,38 snake/pitfall/month). At Rio Pitinga, Amazonas, over 600 amphibians and reptiles were caught in 50 pitfalls (100-150 L, with drift fence) during three months (capture efficiencies of ca. 4.00 amphibians and reptiles/pitfall/month and $0.87 \mathrm{snake} / \mathrm{pitfall} /$ month). Capture efficiencies of 1.25 to -3.92 amphibians and reptiles/pitfall/month were obtained in four other unpublished studies made by other authors in Brazil, all of them using 20-35 L traps, either with or without drift fences. Higher capture efficiencies for snakes were obtained in those studies in which larger containers (100-200 L) were used. The results presented here indicate that pitfall traps are extremely useful to sample amphibians and reptiles in Brazil, especially anurans and lizards. From these results, it is possible to preview the capture of 125 to 1200 amphibians and reptiles with 100 pitfalls during one month, regardless of the size of the pitfalls and sampling design of the trap arrays. The main advantages and disadvantages of the method and detailed guidelines on how to design, install, and use the traps is discussed.

KEY WORDS. Traps, communities, lizards, snakes, amphibians, herpetofauna, Brazil
\end{abstract}

Armadilhas de interceptação e queda consistem de recipientes enterrados no solo (pitfalls) e interligados por cercas-guia (drift-fences; CORN 1994). Quando um pequeno animal se depara com a cerca, geralmente a acompanha, até eventualmente cair no recipiente mais próximo. Estas armadilhas são amplamente utilizadas para a amostragem de anfíbios, répteis e pequenos mamíferos (e.g. SEMLITSCH et al. 1981; MENGAK \& GUYNN 1987; WILliamS \& BRAUN 1983). Uma das vantagens do método é a captura de animais que raramente são amostrados através dos métodos tradicionais que envolvem procura visual (CAMPBELL \& CHRISTMAN 1982).

1) Departamento de Biologia, Centro de Ciências Naturais e Exatas, Universidade Federal de Santa Maria. Estrada de Camobi, Km 9, Camobi, 97105-900 Santa Maria, Rio Grande do Sul, Brasil. E-mail: cechinsz@ccne.ufsm.br

2) Departamento de Ecologia, Instituto de Biociências, Universidade de São Paulo. Caixa Postal 11461, 05422-970 São Paulo, São Paulo, Brasil. E-mail: jararaca@ib.usp.br

Revta bras. Zool. 17 (3): 729 - 740, 2000 
Armadilhas de queda, com ou sem cercas-guia, podem ser utilizadas em vários tipos de estudos (CAMPBELl \& CHRISTMAN 1982; CORN 1994), incluindo levantamentos de riqueza, comparações de abundância relativa, estudos que envolvem marcação e recaptura (e.g. ecologia de populações, monitoramento), estudos sobre atividade sazonal e amostragens de presas potenciais de carnívoros. Em alguns casos, como ecologia de populações e monitoramento, não é necessário o uso de cercas-guia (ver CORN 1994). VOGT \& HINE (1982) chamam a atenção para o importante fato de que o uso de armadilhas de queda elimina os vieses causados pelas variações, entre coletores, na capacidade de encontrar animais visualmente.

Embora freqüentemente utilizadas em ambientes temperados (GIBBONS \& BenNetT 1974; CAMPBEll \& Christman 1982; Vogt \& Hine 1982), armadilhas de queda foram pouco utilizadas para amostrar anfíbios e répteis no Brasil, e sua eficiência nunca foi relatada em detalhes. Neste trabalho, apresenta-se os resultados obtidos com o uso destas armadilhas em estudos realizados no Rio Grande do Sul, em São Paulo e no Amazonas, comparando-os aos resultados de estudos ainda inéditos, realizados em outras regiões brasileiras. Também discute-se as vantagens e desvantagens do método e fornece-se recomendações sobre a construção e utilização das armadilhas.

\section{MATERIAL E MÉTODOS}

O primeiro estudo foi conduzido na região de Santa Maria $\left(29^{\circ} 43^{\prime} \mathrm{S}\right.$, $53^{\circ} 42^{\prime} \mathrm{W}$ ), Rio Grande do Sul, em área coberta por mata mesófila e campo (pastos). Uma série de armadilhas foi instalada em cada um dos três ambientes amostrados: campo, mata e transição campo-mata. Cada série consistia de uma linha contínua composta de dez barris de plástico de $200 \mathrm{~L}$ (medindo cerca de $100 \mathrm{~cm}$ de altura e $60 \mathrm{~cm}$ de diâmetro) dispostos a cada $15 \mathrm{~m}$ e interligados por cerca guia construída com tela plástica de $1 \mathrm{~m}$ de altura. A cerca passava sobre a boca de cada barril. Entre setembro de 1996 e fevereiro de 1998, estas armadilhas permaneceram abertas continuamente e foram inspecionadas três vezes a cada semana. Todos os animais capturados nas armadilhas foram fixados e preservados para estudos posteriores. Estes exemplares foram depositados na coleção do Setor de Zoologia do Departamento de Biologia da Universidade Federal de Santa Maria (ZUFSM).

O segundo estudo (ainda em andamento; aqui são apresentados resultados parciais) foi realizado em Itirapina $\left(22^{\circ} 15^{\prime} \mathrm{S}, 47^{\circ} 49^{\prime} \mathrm{W}\right)$, São Paulo, em área de cerrado. As amostragens foram realizadas em nove pontos amostrais, distribuídos em campo sujo, campo cerrado e em áreas adjacentes a matas ciliares, três pontos em cada fisionomia; os resultados preliminares aqui apresentados referem-se às três fisionomias em conjunto. Cada ponto amostral consistia de duas linhas de quatro baldes de $100 \mathrm{~L}$ enterrados a intervalos de $15 \mathrm{~m}$ e ligados por tela plástica $(45 \mathrm{~m}$ de comprimento e $0,5 \mathrm{~m}$ de altura), totalizando 18 linhas, 72 baldes e $810 \mathrm{~m}$ de cercas-guia. A cerca-guia passava sobre a boca de cada balde (Fig. 1). Entre 27 de agosto de 1999 e 2 de março de 2000, estas armadilhas permaneceram abertas por 44 dias e foram inspecionadas por 1-10 dias a cada mês. Animais capturados nas armadilhas foram fixados e preservados para estudos posteriores ou marcados e soltos ao lado das armadilhas. Os exemplares preservados foram depositados nas coleções do Museu de História Natural da Universidade Estadual de Campinas (ZUEC) e do Instituto Butantan (IB). 


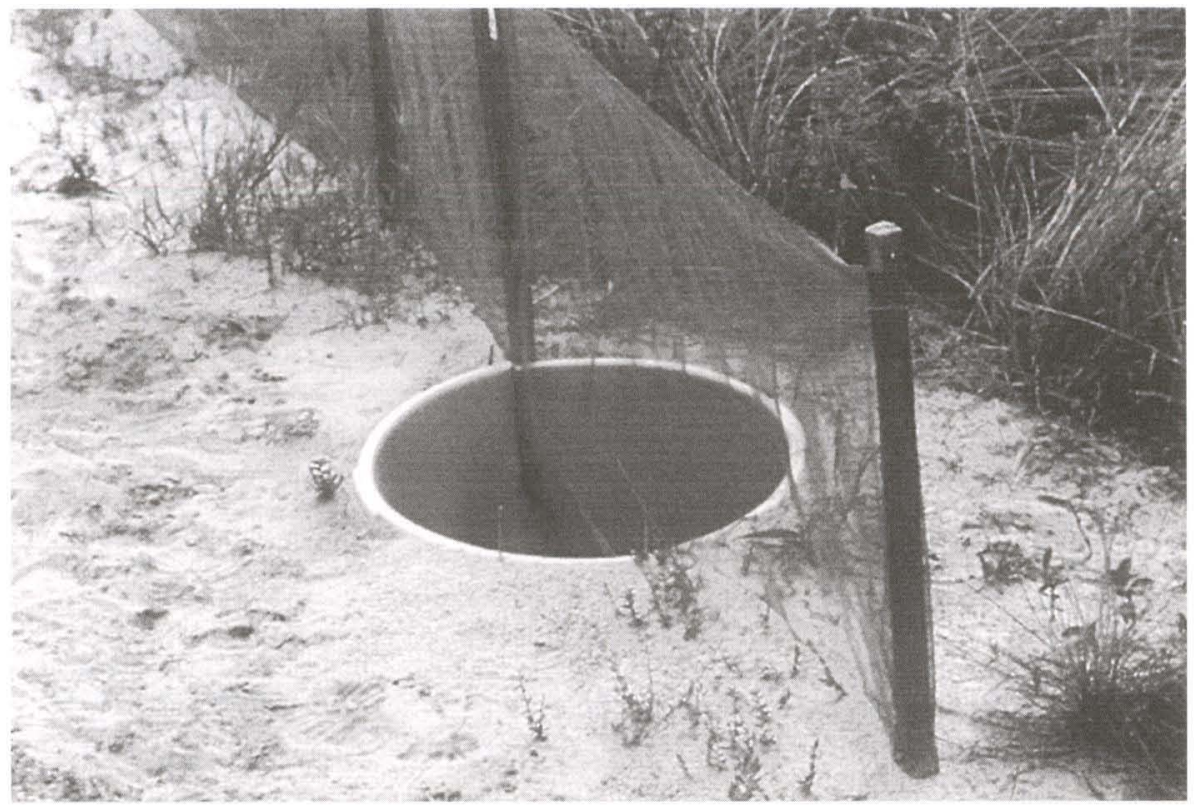

Fig. 1. Detalhe de extremidade de uma linha de armadilhas de queda com cerca-guia (baldes de $100 \mathrm{~L}$ e tela plástica de $60 \mathrm{~cm}$ de altura), instalada na Estação Ecológica de Itirapina, Itirapina, São Paulo. Note que a borda do balde fica ao nível do solo.

O terceiro estudo foi conduzido no rio Pitinga $\left(0^{\circ} 40^{\prime} \mathrm{S}, 59^{\circ} 20^{\prime} \mathrm{W}\right)$, Presidente Figueiredo, Amazonas, em mata primária de terra firme (ver MARTINS \& OLIVEIRA 1999). A área de estudo consiste de uma série de ilhas artificiais formadas pelo enchimento do reservatório que alimenta uma pequena usina hidrelétrica. As armadilhas foram confeccionadas com tonéis de metal cortados ao meio ou no quarto superior (100-150 L), instalados a cada $10 \mathrm{~m}$ e interligados por cerca de tela de plástico de $100 \mathrm{~cm}$ de altura (ver figura $4 \mathrm{em}$ MARTins \& OLIVEIRA 1999). Cada linha de armadilhas tinha 50 a 100 m de extensão, totalizando aproximadamente $500 \mathrm{~m}$ de cerca e 50 tonéis. As armadilhas permaneceram abertas ininterruptamente entre o final de setembro e o final de dezembro de 1991 e foram inspecionadas diariamente. Todos os animais capturados nas armadilhas foram fixados e depositados nas coleções do Instituto de Medicina Tropical de Manaus (IMTM) e do Instituto Nacional de Pesquisas da Amazônia (INPA).

\section{RESULTADOS}

Um total de 2.040 anfíbios e répteis foi capturado nas armadilhas durante os 18 meses de estudo em Santa Maria: 1.911 anfíbios anuros de 17 espécies, 77 serpentes de 20 espécies e 52 lagartos de cinco espécies (taxa de captura geral de 3,78 anfíbios e répteis/recipiente/mês; Tab. I). Portanto, 42 espécies de anfíbios e répteis foram amostradas nas armadilhas. Os números de espécies amostradas representam, respectivamente, $94 \%, 80 \%$ e $83 \%$ das espécies de anfíbios, serpentes 
e lagartos até agora encontrados na área através de três métodos de amostragem: armadilhas de queda, coletas por terceiros e procura visual. Além dos anfíbios e répteis, 145 pequenos mamíferos foram capturados nas armadilhas. A maior serpente capturada media $917 \mathrm{~mm}$ de comprimento total.

Em Itirapina, foram capturados 1.262 anfíbios e répteis durante os 6 meses de estudo: 1.148 anfíbios anuros de 14 espécies, 40 serpentes de 14 espécies e 74 lagartos de dez espécies (taxa de captura geral de 11,96 anfíbios e répteis/recipiente/mês; Tab. I). Portanto, 38 espécies de anfíbios e répteis foram amostradas nas armadilhas. Os números de espécies amostradas representam 64\%, 61\% e 100\% das espécies de anfíbios, serpentes e lagartos até agora encontrados na área através de três métodos de amostragem: armadilhas de queda, procura visual e procura em ambientes de reprodução (este último somente para anfíbios). Além dos anfíbios e répteis, 128 pequenos mamíferos foram capturados nas armadilhas. A maior serpente capturada media $749 \mathrm{~mm}$ de comprimento total.

Tabela I. Resumo dos resultados de estudos que utilizaram armadilhas de queda para amostrar anfibios e répteis em localidades brasileiras. $O$ volume corresponde à capacidade dos recipientes utilizados. A duração do estudo corresponde ao número de dias nos quais as armadilhas estavam em uso. Taxa de captura $=$ individuos/recipiente/mês. (PNE) Parque Nacional das Emas; (A) presente estudo; (B) estudo realizado durante enchimento de represa; (C) D. Pavan (comunicação pessoal); (D) P.H. Valdujo, C. Nogueira e R. Brandão (comunicação pessoal); (E) M.T.U. Rodrigues (comunicação pessoal); (F) A. Gambuzzi e V.R. Pivello (comunicação pessoal); (G) cerca em disposição radial.

\begin{tabular}{|c|c|c|c|c|c|c|c|}
\hline \multirow{2}{*}{ Local } & & \multirow{2}{*}{$\begin{array}{c}\text { Ambiente } \\
\text { amostrado }\end{array}$} & \multirow{2}{*}{$\begin{array}{l}\text { Volume } \\
\text { (L) }\end{array}$} & \multirow{2}{*}{ Cerca } & \multirow{2}{*}{$\begin{array}{l}\text { Duração } \\
\text { (dias) }\end{array}$} & \multicolumn{2}{|c|}{ Taxa de captura } \\
\hline & & & & & & Anfíbios e répteis & Serpentes \\
\hline Rio Pitinga, AM & $A, B$ & Mata & $100-150$ & Sim & 90 & $\sim 4,00$ & 0,87 \\
\hline Santa Maria, RS & A & Mata, campo & 200 & Sim & 540 & 3,78 & 0,14 \\
\hline Itirapina, SP & A & Cerrado & 100 & Sim & 44 & 11,96 & 0,38 \\
\hline Serra da Mesa, GO & C, B & Cerrado, mata & 30 & Năo & 96 & $\sim 3,92$ & $\sim 0,04$ \\
\hline PNE, GO, MS & D & Cerrado & 35 & Năo & 7 & 2,11 & 0,03 \\
\hline Aripuană e Juruena, MT & $E$ & Mata & 20 & $\operatorname{Sim} \mathrm{G}$ & 37 & 2,86 & 0,03 \\
\hline Santa Rita do Passa Quatro & $\mathrm{F}$ & Cerrado & 20 & $\operatorname{Sim} \mathrm{G}$ & 36 & 1,25 & 0,17 \\
\hline
\end{tabular}

No rio Pitinga, só foram quantificadas as serpentes, embora mais de 500 anfíbios, lagartos e pequenos mamíferos também tenham sido capturados. Foram obtidas cerca de 130 serpentes de 31 espécies (76\% das espécies obtidas na área pelos mesmos métodos citados acima) durante os três meses nos quais os tonéis permaneceram abertos (Tab. I).

Quatro estudos, ainda inéditos, desenvolvidos por outros autores, empregaram recipientes menores (20-35 L; Tab. I) que aqueles utilizados nos estudos descritos anteriormente. Considerando os sete estudos citados na tabela I, quando todos os grupos de anfíbios e répteis são considerados em conjunto, as taxas de captura variaram de 1,25 a 11,96 indivíduos/recipiente/mês (Tab. I). A taxa de captura para anfíbios e répteis obtida em Itirapina foi muito superior àquelas dos demais estudos (cerca de três vezes maior do que a segunda maior taxa, obtida no Pitinga). Em parte, esse resultado deve ser conseqüência da amostragem praticamente concentrada durante o período de chuvas em Itirapina, o que resulta em maior 
taxa de captura de anfíbios. Taxas de captura relativamente altas também foram obtidas nos dois estudos realizados durante enchimento de represas em usinas hidrelétricas (Pitinga e Serra da Mesa; Tab. I); esses resultados indicam que anfïbios e répteis fogem do avanço da água pelas margens, o que os torna mais suscetíveis às armadilhas de queda. Já as taxas de captura de serpentes foram consideravelmente mais altas nos estudos que utilizaram recipientes maiores (Tab. I); por outro lado, a maior taxa de captura de serpentes no Pitinga deve ser devida ao enchimento da represa (ver acima).

\section{DISCUSSÃO}

\section{Vantagens e limitações do método}

Com base nos resultados, fica evidente que, quando montadas e distribuídas de maneira adequada (ver sugestões abaixo), armadilhas de interceptação e queda são extremamente eficientes em amostragens de anfíbios e répteis, especialmente anuros e lagartos. As eficiências de captura apresentadas na tabela I podem servir de referência para estimativas do esforço de amostragem necessário para capturar um determinado número de anfíbios e répteis. Por exemplo, com cem recipientes inspecionados ao longo de 30 dias é possível capturar 125 a 1.200 anfíbios e répteis nos ambientes citados na tabela I, independentemente do tamanho dos recipientes (de 20 a 200 L) e do desenho dos blocos de armadilhas. Além disso, os estudos em Santa Maria, em Itirapina e no Pitinga indicam que 60-100\% das espécies de anfíbios e répteis de uma dada localidade podem ser capturadas em armadilhas de queda em estudos com grande esforço de campo.

Entretanto, além do preço do material utilizado, cavar um grande número de buracos e instalar centenas de metros de cercas-guia envolvem um trabalho considerável. Assim, quanto maior a duração do estudo, melhor a relação custo-benefício. Por esse motivo, armadilhas de queda não devem ser utilizadas em estudos de curto prazo, como levantamentos de riqueza em períodos inferiores a 20 dias. Outra limitação é o tipo de solo da área de estudo. Em locais pedregosos, o tempo e a energia despendidos na instalação e manutenção desfavorecem seu uso e, em locais alagados, o uso das armadilhas torna-se inviável. Por outro lado, o trabalho despendido na inspeção é pequeno quando comparado à procura visual, por exemplo. No estudo realizado em Santa Maria, considerando o tempo de trabalho efetivo de campo (inspeção), as armadilhas de queda foram cerca de sete vezes mais eficientes na captura de serpentes do que a procura visual (embora através deste último método seja possível obter informações adicionais sobre microhabitat, atividade e comportamento para cada animal encontrado).

Em levantamentos de riqueza, espécies muito pequenas (que sejam capazes de fugir através dos orifícios de drenagem dos recipientes) ou espécies cujos filhotes já nascem muito grandes (e, portanto, poderiam escapar de recipientes pequenos; ver abaixo) dificilmente serão amostradas. Com relação às serpentes, a altura dos recipientes utilizados parece ser importante na determinação do tamanho máximo dos indivíduos capturados (GiBBONS \& SEMLITSCH 1982); de fato, taxas de captura de serpentes foram mais altas nos estudos aqui apresentados que utilizaram reci- 
pientes maiores (ver Tab. I). Por esses motivos, outros métodos devem ser utilizados em conjunto com as armadilhas de queda em levantamentos de riqueza, especialmente a procura visual (ver CAMPBELL \& CHRISTMAN 1982) e as coletas por terceiros (ver CuNHA \& NASCIMENTO 1978). Qualquer que seja o método utilizado (ou uma combinação de métodos), curvas de acumulação de espécies (ver HAYEK \& BUZAS 1997) são de grande utilidade para avaliar a abrangência das amostragens.

O período de amostragens também pode ter forte influência nas taxas de captura, especialmente para grupos com atividade tipicamente sazonal, como a maioria dos anfíbios (ver CORN 1994). Assim, dependendo dos objetivos da amostragem, um planejamento levando em conta a sazonalidade do grupo a ser amostrado pode levar à obtenção de altas taxas de captura em um curto período (como parece ter ocorrido no estudo em Itirapina). Por exemplo, amostragens realizadas durante os meses de maior pluviosidade resultarão em maiores taxas de captura de anfíbios do que aquelas feitas em meses de menor pluviosidade.

É importante notar que pode ocorrer predação entre os animais capturados nas armadilhas de queda. Por exemplo, serpentes podem ingerir anfíbios e lagartos e estes últimos podem ingerir invertebrados. Na falta de estudos conclusivos sobre essa possibilidade, deve-se evitar a utilização de exemplares obtidos nestas armadilhas para estudos de dieta, a não ser que as inspeções sejam feitas várias vezes ao dia. Uma alternativa é o uso de solução de formalina nos baldes, que leva os animais capturados à morte em poucos minutos, evitando eventuais predações. Entretanto, esse método inviabiliza estudos que dependam de animais vivos.

Em qualquer caso, como ocorre com qualquer método de amostragem, os resultados obtidos por armadilhas de queda são sempre tendenciosos para a fauna suscetível às mesmas (ver discussões em CAMPBELl \& CHRISTMAN 1982; GREENBERG et al. 1994). Neste caso, somente são amostrados os animais que se deslocam sobre o chão ou pela camada mais superficial do solo. Animais que se deslocam principalmente pela vegetação ou pelas camadas mais profundas do solo raramente são amostrados (no rio Pitinga, por exemplo, apenas 6\% das serpentes amostradas eram arborícolas ou semiarborícolas). Além do tamanho, o comportamento dos animais-alvo também pode influenciar a suscetibilidade à captura: animais muito sedentários, como boa parte dos caçadores de espreita, são menos amostrados. Como conseqüência dessas limitações, as abundâncias relativas obtidas com armadilhas de interceptação e queda refletirão esta seletividade. Portanto, os resultados de abundância relativa só devem ser comparados com aqueles obtidos com o mesmo tipo de armadilha.

A efetividade das armadilhas depende, também, da composição da fauna a ser amostrada. Em comunidades com muitas espécies arborícolas (e.g. serpentes na América Central, com predominância de dipsadíneos), uma menor porcentagem do total de espécies será amostrada. Por outro lado, em comunidades onde predominam espécies terrestres (e.g. serpentes na metade meridional da América do sul, com muitos xenodontíneos; ver exemplos de ambos os casos em CADLE \& GREENE 1993), a maior parte das espécies será amostrada; nos estudos em Itirapina e Santa Maria, 61 e $80 \%$ das espécies de serpentes conhecidas para estas áreas, respectivamente, foram amostradas com as armadilhas de interceptação e queda. De modo 
semelhante, em ambientes com pouca estruturação vertical (e.g. pampas, formações abertas de cerrado, campos de altitude), armadilhas de queda devem ser mais efetivas para amostragens de riqueza do que em florestas.

\section{Construção e utilização das armadilhas}

Como a construção e detalhes da utilização das armadilhas podem influenciar os resultados a serem obtidos (GREENBERG et al. 1994; observação pessoal), fornecemos a seguir uma série de recomendações para a construção e o uso adequado de armadilhas de interceptação e queda (ver Tab. I).

Embora geralmente sejam utilizados recipientes de volume relativamente pequeno (20-35 L; e.g. CAMPBELl \& Christman 1982; GREENBERG et al. 1994; MENGAK \& GUYNN 1987; estudos citados na tabela I), o uso de recipientes de 100 a $200 \mathrm{~L}$ possibilita a captura de animais de um maior espectro de tamanhos. Mesmo com recipientes de $200 \mathrm{~L}$, adultos de serpentes que atingem grande porte dificilmente serão amostrados. Entretanto, indivíduos menores destas mesmas espécies estarão suscetíveis às armadilhas, exceto para aquelas cujos jovens já nascem grandes demais para serem capturados (e.g. alguns boídeos). O maior trabalho envolvido na instalação de recipientes maiores pode ser compensado pela maior quantidade e variedade de animais capturados.

Recipientes adequados são lixeiras, baldes ou tambores de plástico. Independente do tamanho, a boca do recipiente deve ficar ao nível do solo (Fig. 1). Em terrenos com declividade acentuada, o solo ao redor do recipiente deve ser aplanado ou, ainda, a parte superior do recipiente deve ser cortada de forma a acompanhar a declividade. Quando o recipiente é encaixado no buraco recém aberto, usa-se parte do solo removido para preencher os espaços vazios ao redor do recipiente. Outra parte desse solo pode ser utilizado para tapar a vala na qual a base da cerca é enterrada (ver abaixo) e o solo restante deve ser removido dos arredores das armadilhas.

É sempre recomendável a realização de orifícios ou cortes no fundo ou nas laterais da base do recipiente, por onde a água de chuva eventualmente acumulada escoará para o solo. Estes orifícios ou cortes devem, entretanto, ser grandes o suficiente para que não sejam facilmente obstruídos por detritos, e pequenos o suficiente para impedir que pequenos animais alongados (gimnofionas, anfisbenas, lagartos e serpentes) escapem pelos mesmos; orifícios de 3-4 mm parecem ser adequados e são facilmente feitos com furadeiras elétricas. Detritos eventualmente acumulados no fundo do recipiente devem ser periodicamente removidos e os orifícios ou cortes, desobstruídos.

Quanto à cerca, telas ou lonas plásticas são adequadas; as lonas geralmente podem ser encontradas por menor preço, mas seu manuseio é mais difícil, especialmente para manter uma cerca alta na posição vertical. Em locais com ventos constantes e/ou fortes, as telas de plástico são mais apropriadas por permitirem a passagem do vento. Por outro lado, lagartos têm maior facilidade de escalar uma tela e evitar, assim, sua queda na armadilha. A altura da cerca depende do tipo e do tamanho dos animais a serem amostrados: para a maioria dos anfíbios e lagartos, cercas de 50 a 60 cm são suficientes, mas para as cobras de tamanho médio a grande, a cerca deve ter 100 a $120 \mathrm{~cm}$ de altura. É muito importante que a base da cerca seja 
enterrada, idealmente a pelo menos $10 \mathrm{~cm}$ de profundidade (Fig. 2); para isso, recomendamos a construção de uma vala, com enxada ou pá de corte, onde a cerca é encaixada e os espaços laterais são preenchidos com solo* e posteriormente socados. A cerca deve ser mantida em posição vertical em toda sua extensão (Fig. 1); para tanto, podem ser utilizadas estacas de madeira ou metal, nas quais a tela é fixada com fios de metal ou com grampeadores de tapeceiro. Outra alternativa é fazer um sulco na porção superior da estaca de madeira, com um pequeno serrote, para o encaixe de um fio de metal que traspassa a borda superior da cerca ao longo de todo seu comprimento. A vegetação ao longo da cerca deve ser retirada, já que anfíbios e répteis poderiam utilizá-la como "ponte" para transpor a cerca-guia.

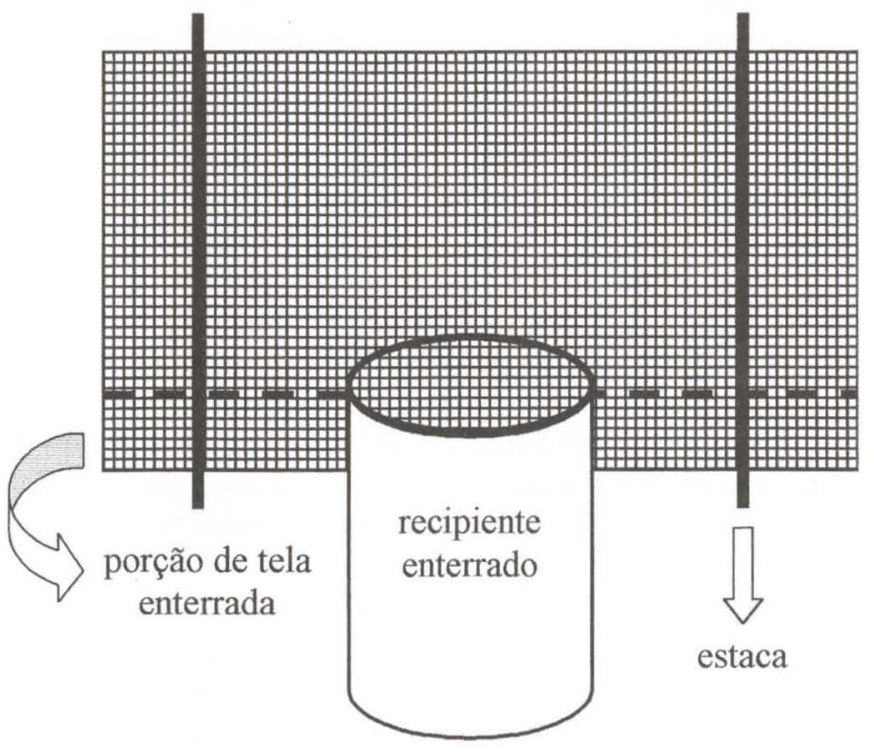

Fig. 2. Detalhe esquemático de um trecho de armadilha de queda com cerca-guia, na qual a cerca passa pela parte superior do recipiente. A linha tracejada representa o nivel do solo.

A colocação do recipiente pode se dar adjacente (recipientes pequenos) ou abaixo da cerca-guia (recipientes grandes); neste último caso, a cerca divide a boca do recipiente em duas porções iguais, cada uma exposta de um lado da cerca (Figs 1-3), sendo necessário realizar cortes na borda do recipiente (com um serrote, por exemplo) onde a cerca é encaixada.

É importante que todos os materiais utilizados nas armadilhas mantenham-se em boas condições durante todo o estudo. Neste sentido, o uso de materiais que oxidam ou deterioram-se rapidamente deve ser evitado. Particularmente, devem ser evitados arames ou grampos oxidáveis, estacas de madeira de baixa qualidade e baldes de plástico muito fino (o plástico da maioria dos baldes de 15 a $30 \mathrm{~L}$ torna-se quebradiço em curto período de tempo). Com materiais adequados, o trabalho com a manutenção da estrutura das armadilhas é mínimo. 
Existem na literatura várias sugestões de disposições de armadilhas de interceptação e queda, sendo as mais comuns as linhas e as disposições radiais (CAmpbell \& Christman 1982; Corn 1994; Greenberg et al. 1994; Fig. 3). A disposição a ser utilizada depende em grande parte dos objetivos do trabalho: em estudos nos quais é necessário o uso de réplicas de pontos amostrais, séries curtas, em linha ou radiais, são as mais adequadas. É importante lembrar que para que as réplicas sejam independentes, a chance de um mesmo animal ser interceptado por armadilhas de mais de um ponto amostral deve ser inexistente ou desprezível. Neste sentido, distâncias de 300 a 500 m entre pontos amostrais parecem ser adequadas para a maioria dos anfíbios e répteis. Se não forem necessárias réplicas, linhas longas podem ser utilizadas, facilitando a construção e as inspeções posteriores. Um desenho amostral adequado para estudos que dependem de réplicas (ver HAYEK \& BUZAS 1997) e, geralmente de fácil instalação, é a distribuição dos pontos amostrais ao longo de trilhas, cada ponto composto por duas a quatro séries curtas de armadilhas (Fig. 4). A localização e o sentido de cada série de armadilhas no caso de disposição em linha, podem ser sorteados ou distribuídos sistematicamente em cada ponto de amostragem. É importante salientar que para se obter uma amostra representativa do ambiente a ser estudado não se deve escolher os pontos de amostragem no campo, pois isso resultaria em super-amostragem das fisionomias escolhidas. Portanto, idealmente, o desenho amostral ao longo das trilhas deve ser determinado previamente. Posteriormente, vai-se ao campo e instala-se as séries de armadilhas nos pontos exatos definidos anteriormente.

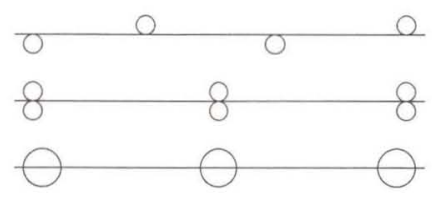

A

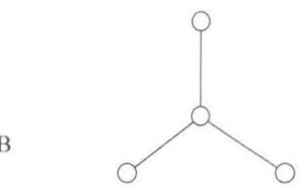

Fig. 3. Exemplos de disposição de armadilhas de queda. As linhas representam cercas-guia e os circulos, recipientes. A: disposições em linha. B: disposição radial.

Armadilhas instaladas em áreas abertas podem possuir coberturas que façam sombra dentro do recipiente, evitando assim a superexposição dos animais capturados. As próprias tampas dos recipientes podem ser utilizadas, desde que fiquem suspensas $(10-15 \mathrm{~cm})$ sobre a boca do recipiente, com o auxílio de quatro pequenas estacas de madeira, por exemplo. Nos casos em que a cerca é encaixada em cortes no recipiente, a tampa deve ser cortada ao meio. Outra alternativa é o uso de pequenas placas de isopor colocadas no fundo da armadilha e mantidas a $3-5 \mathrm{~cm}$ de altura com o auxílio de pequenas estacas, de modo que os animais capturados 
possam se abrigar sob estas placas. Em matas com dossel fechado, não é necessária a utilização de tampas ou placas de isopor. Um pote raso com água deve ser colocado dentro de cada recipiente em ambientes secos (e.g. cerrado), de modo a evitar que anfíbios morram por dessecação.

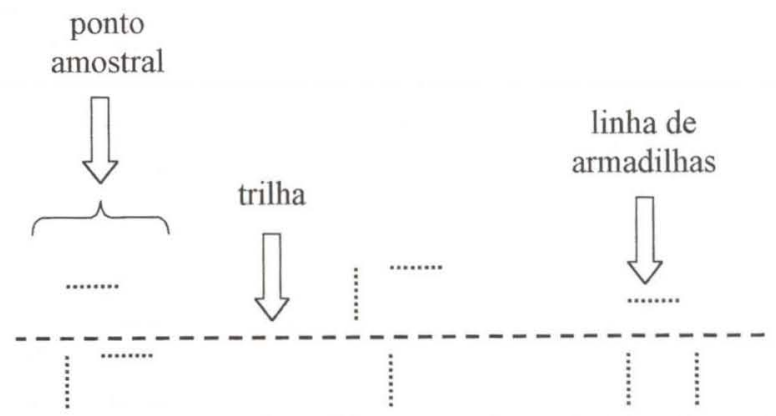

Fig. 4 Distribuição de pontos amostrais eqüidistantes ao longo de trilhas, baseada em sugestão de HAYEK \& BUZAS (1997). Cada ponto amostral, neste caso, é composto por três linhas curtas de armadilhas, cuja posição e orientação, em cada ponto, é sorteada (sobre a distância entre os pontos amostrais, ver texto).

Armadilhas de interceptação e queda capturam, além de anfíbios e répteis, vários outros pequenos animais, incluindo escorpiões e aranhas que podem representar perigo durante a inspeção. Por isso, recomendamos que a inspeção se faça da seguinte maneira: com um bastão, os detritos acumulados são revolvidos para a detecção de animais eventualmente capturados; localizados os animais de interesse, os mesmos são colhidos com pinças ou com as mãos protegidas por luvas de raspa de couro; os animais que não são de interesse para o estudo devem ser removidos e libertados. Serpentes podem ser removidas manualmente (por pessoas que sabem distinguir seguramente espécies venenosas) ou com auxílio de ganchos ou de pinções ("jacarés"), especialmente no caso de serpentes venenosas. Neste caso, deve-se atentar para o fato de que jararacas (e, certamente, cascavéis) são capazes de perfurar luvas de raspa de couro com suas presas inoculadoras de veneno (MARTINS \& OLIVEIRA 1999). Recomendamos, ainda, uma inspeção cuidadosa ao longo da base da cerca-guia, onde é relativamente comum o encontro de anfíbios e répteis, incluindo serpentes venenosas.

Idealmente, as inspeções das armadilhas devem ser feitas diariamente. Entretanto, inspeções a cada dois ou três dias também são possíveis, embora possa ocorrer a morte e o apodrecimento de alguns exemplares ou predação dentro das armadilhas. Além disso, predadores podem invadir as armadilhas para se alimentar dos animais capturados. No rio Pitinga, formigas carnívoras e, em Santa Maria, mamíferos e aves de rapina predaram animais capturados nas armadilhas. A colocação de graxa formando um anel por dentro do recipiente poderia impedir o acesso de formigas. Por outro lado, as tampas dos recipientes, colocadas a $10-15 \mathrm{~cm}$ sobre a boca dos mesmos (ver acima), poderiam dificultar o acesso de mamíferos e aves. A freqüência de inspeções das armadilhas também depende dos objetivos do estudo: quando se deseja conhecer o horário de atividade dos animais a serem capturados, por exemplo, devem ser feitas inspeções em diferentes horários do dia. 
Após chuvas fortes, uma coluna d'água, de altura variável, pode permanecer no fundo do recipiente por várias horas ou até alguns dias. A porosidade e o grau de compactação do solo, além do tamanho dos orifícios no fundo do recipiente, determinam a quantidade de água eventualmente acumulada. Sempre que haja a possibilidade de inundações mais duradouras, como quando se instala armadilhas em terreno no qual o lençol freático encontra-se muito próximo à superfície, recomendamos a colocação de pedaços de isopor grosso (3 $\mathrm{cm}$ de espessura) no fundo do recipiente, sobre o qual os animais podem se abrigar da água.

Finalmente, recomendamos enfaticamente que, ao final do estudo, as armadilhas sejam desmontadas, todo o material seja removido da área de estudos e os buracos que alojavam os recipientes sejam preenchidos.

AGRADECIMENTOS. No estudo em Santa Maria, Paulo Hartmann, Luis Giasson, Emerson Cassol, Aline Mallmann, Janaine Melchiors, Marília Almeida, Isadora Melo e Dilson Cechin ajudaram na instalação e inspeção das armadilhas. Em Itirapina, Ricardo J. Sawaya, Cinthia A. Brasileiro, Luciano A. dos Anjos, M. Ermelinda Oliveira e Vinícius Bonato ajudaram na instalação e realizaram a inspeção das armadilhas. No rio Pitinga, os funcionários do Núcleo de Animais Peçonhentos, Instituto de Medicina Tropical de Manaus, ajudaram na instalação e inspeção das armadilhas. Resultados inéditos foram gentilmente fornecidos por Alberta Gambuzzi, Cristiano Nogueira, Dante Pavan, Miguel T.U. Rodrigues, Paula H. Valdujo, Reuber Brandão e Vânia R. Pivello. Otávio A.V. Marques, M. Ermelinda Oliveira e dois revisores anônimos sugeriram alterações que melhoraram sensivelmente a versão final do manuscrito. Sugestões adicionais foram fornecidas por Cristiano Nogueira. Miguel T.U. Rodrigues discutiu questões práticas relacionadas a armadilhas de queda. O apoio da FAPESP (processo $\mathrm{n}^{\circ}$ 1995/09642-5) foi essencial para o trabalho em Itirapina e a preparação do manuscrito; esta é a publicação número 1 do projeto "Ecologia dos Cerrados de Itirapina", desenvolvido pelo Departamento de Ecologia do Instituto de Biociências da Universidade de São Paulo.

\section{REFERÊNCIAS BIBLIOGRÁFICAS}

Cadle, J.E. \& H.W. Greene. 1993. Phylogenetic patterns, biogeography, and the ecological structure of neotropical snake assemblage, p. 281-293. In: R.E. RickLefs \& D. SCHLuter (Eds). Species diversity in ecological communities: historical and geographical perspectives. Chicago, Univ. Chicago Press, 416p.

CAMPBELL, H.W. \& S.P. CHRISTMAN. 1982. Field techniques for herpetofaunal community analysis, p. 193-200. In: N.J. SCOTT JR. (Ed.). Herpetological communities. Washington, U.S. Fish Wild. Serv. Wildl. Res. Rep. 13, IV+239p.

CoRn, P.S. 1994. Straight-line drift fences and pitfall traps, p. 109-117. In: W.R. HEYLR; M.A. DonNELY; R.W. MCDiarmid; L.-A. HAYEK \& M. Fuster (Eds). Measuring and monitoring biological diversity: standard methods for amphibians. Washington, D.C., Smithsonian Institution Press, $\mathrm{XIX}+364 \mathrm{p}$.

Cunila, O.R. \& F.P. Nascimento. 1978. Ofĩdios da Amazônia X - As cobras da região leste do Pará. Publ. Avul. Mus. Par. Emílio Goeldi 31: 1-218.

GibBons, J.W. \& D.H. BENNETT. 1974. Determination of anuran terrestrial activity patterns by a drift fence method. Copeia 1974: 236-243.

GibBons, J.W. \& R.D. SEmLitscit. 1982. Terrestrial drift fences with pitfall traps: an effective technique for quantitative sampling of animal populations. Brimleyana 1982: 1-16.

Revta bras. Zool. 17 (3): 729 - 740, 2000 
Greenberg, C.H.; D.G. Neary \& L. D. Harris. 1994. A comparison of herpetofaunal sampling effectiveness of pitfall, single-ended, and double-ended funnel traps used with drift fences. Jour. Herpetol. 28: 319-324.

HAYEK, L.A. \& M.A. BuZAS. 1997. Surveying natural populations. New York, Columbia University Press, XVII +563p.

Martins, M. \& M.E. OliveiRA. 1999 (datado 1998). Natural history of snakes in forests of the Manaus region, Central Amazonia, Brazil. Herpetol. Nat. Hist. 6: 78-150.

MengaK, M.T. \& D.C. GuYnN JR. 1987. Pitfalls and snap traps for sampling small mammals and herpetofauna. Amer. Midl. Nat. 118: 284-288.

Semi.ITSCH, R.D.; K.L. Brown \& J.P. CAt.DWell. 1981. Habitat utilization, seasonal activity and population size structure of the southeastern crowned snake Tantilla coronata. Herpetologica 37: 40-46.

VoGT, R.C. \& R.L. HinE. 1982. Evaluation of techniques for assessment of amphibian and reptile populations in Wisconsin, p. 201-217. In: N.J. SCOTT JR. (Ed.). Herpetological communities. Washington, U.S. Fish Wild. Serv. Wildl. Res. Rep. 13, IV+239p.

Williams, D.F. \& S.E. BRAUN. 1983. Comparison of pitfall and conventional traps for sampling small mammal populations. Jour. Wildl. Manage. 47: 841-845.

Recebido em 17.VI.1999; aceito em 25.VIII.2000. 